\title{
9. A EXPRESSÃO “UMA LIBRA DE CARNE” NA OBRA O MERCADOR DE VENEZA: METÁFORA OU LITERALIDADE? EIS A QUESTÃO!
}

9. THE EXPRESSION "A POUND OF FLESH" IN THE "MERCHANT OF VENICE: IS IT A METAPHOR OR LITERAL EXPRESSION? THAT IS THE QUESTION!

Ângela Kretschmann ${ }^{1}$

Celso Augusto Nunes da Conceição

\begin{abstract}
Resumo: Pretendendo (re)direcionar o final da obra de William Shakespeare em O Mercador de Veneza, sem que a trama contratual seja desfeita na sua origem, insere-se a questão linguística no seu aspecto semântico: a metáfora do termo "uma libra de carne". A partir daí, o personagem que provocou toda a questão jurídica envolvendo a lei e o poder, Shylock, pôde se utilizar desse recurso linguístico na contra-argumentação das determinações de Porcia $^{3}$ na cena do juízo, não para seu benefício, mas para diminuir a penalidade imposta. Os diálogos reescritos com a roupagem semântica pró-réu levam o leitor a uma nova reflexão.

Palavras-chave: Uma libra de carne, Literalidade e Metáfora
\end{abstract}

\begin{abstract}
Trying to (re)direct the end of the play of William Shakespeare in The Merchant of Venice, preventing that the contractual plot is undone in its origin, we place the language issue in their semantic aspects: the metaphor of the term "a pound of flesh". From this point of view, the character that caused the entire legal matter involving the law and power, Shylock, could usethat language resource in the counter-argument of the determinations of Portia in the judgment scene, not for his benefit, but to decrease the penalty which was imposed. The dialogues with semantic perspective rewritten pro-defendant lead the reader to rethink the comndenation

Keywords: A pound of flesh, Literality and Metaphor.
\end{abstract}

\section{Breve sinopse da obra $O$ Mercador de Veneza}

No século XVI, Shakespeare escreveu a peça intitulada O Mercador de Veneza. Começa com Bassanio querendo cortejar Pórcia, herdeira do rico Belmont, mas está sem

\footnotetext{
${ }^{1}$ Professora e Coordenadora do Curso de Direito do Cesuca, Mestre em Direito pela PUC/RS, Doutora em Direito pela Unisinos/RS, Pós-doutora pelo Institut for Information-, Telecommunication- and Media Law (ITM), Münster, Alemanha. E-mail: angelak@unisinos.br

2 Professor das disciplinas de Português Jurídico e Direito e Linguagem no Cesuca, Mestre e Doutor em Linguística Aplicada na PUCRS. E-mail: celsus@terra.com.br

${ }^{3}$ Ou Pórtia (Portia), dependendo de quem traduziu o texto original. 
dinheiro. Então recorre ao seu amigo Antonio, que, apesar de ser rico, não consegue emprestar do seu dinheiro para o amigo porque está comprometido com investimentos em no exterior, mas resolve o problema pedindo um empréstimo de três mil ducados ao judeu Shylock. Este aguardava ansiosamente uma oportunidade para se vingar de Antonio, que o maltratava muito em função de ser cristão e Shylock um judeu, que era agiota, impondo condição fora dos padrões éticos e morais: caso o empréstimo não for pago no prazo de três meses, Antonio dará um pedaço de sua própria carne a Shylock.

O pior aconteceu: os navios de Antônio naufragaram e o deixaram numa posição desconfortável, para não dizer que a situação estava muito complicada. Bassânio fica sabendo disso por carta enviada pelo próprio Antônio. Fica desesperado e fala com Pórcia, que o tenta acalmar e pagar Shylock, que aproveita o caso e leva seu devedos à corte para que a penalidade seja reconhecida pela justiça a fim de que ele próprio possa aplicar a referida multa.

Começa aí o problema! Shylock não quer a multa financeira, quer arrancar uma libra de carne, pois seu ódio pelos cristãos, principalmente a Antônio, é muito forte.

Sabendo que ele quer mutilar o seu devedor, Pórcia resolve ela mesma fazer a defesa de Antônio na corte. Ela e Nerissa, sua dama de companhia, vestem-se de homens e vão à corte disfarçadas. Consegue argumentar para que ele não execute o seu plano, fazendo com que,, além de não conseguir tirar "a libra de carne" de seu inimigo, também deixá-lo sem dinheiro.

Nesse meio tempo, Jéssica, a filha de Shylock, enamora-se com Lourenço e parte com ele levando boa parte do dinheiro do pai. Shylock fica muito mais furioso e, claro, quer uma vingança maior porque acredita que Antônio a ajudou a fugir.

Já no tribunal, Pórcia, substituindo o Doutor Baltazar, começa a ler o contrato em voz alta. Consegue persuadi-lo com uma manobra jurídica, mas ilegal, e fazê-lo, além de não conseguir o seu objetivo, ainda deixar metade de sua herança para Jéssica e Lorenzo. Doge perdoa Shylock.

Depois do julgamento há um problema com um anel que foi deixado pela Pórcia para Bassânio e ele não o tinha mais, mas pergunta a Antonio sobre a fidelidade de seu esposo e fica feliz porque garante que Bassânio é fiel.

No final, Pórcia conta toda a verdade a Baltazar e junta-se a Bassânio para compor com os outros dois casais, Lorenzo e Jéssica e Nerissa e Graziano para compartilhar a felicidade em conjunto. 
Apesar de existirem várias traduções do livro em questão, foram selecionados dois tradutores ${ }^{4}$ em particular, os que mais se aproximaram em termos de significação, principalmente para os objetivos deste estudo.

\section{Algumas fontes históricas e precursoras da obra de Shakespeare}

O autor de $O$ mercador de Veneza inspirou-se na coleção de contos de Ser Giovanni, escrita em língua italiana aproximadamente em 1378, tendo o nome de II Pecorone. Nela está a expressão que ele se utilizou para a penalidade que Shylock impôs a Antônio: "uma libra de carne". Essas afirmações estão baseadas na dissertação de Bonacin $(2012)^{5}$, conforme seu excerto:

(...) Shakespeare tomou emprestada a história da penhora de uma libra de carne humana, bem como suas circunstâncias e a exigência do judeu para o seu cumprimento, e também o incidente do anel de casamento e a dama de Belmonte. Portanto, a versão mais próxima, de uma forma geral, de $O$ mercador de Veneza, é, sem dúvida, II Pecorone. Tal obra assemelha-se em tantos detalhes à peça de Shakespeare que se pode considerá-la a sua fonte principal.

Ainda segundo Bonacion (2012), outras versões sobre o pagamento de dívidas com parte do corpo humano, especificamente "uma libra de carne", são encontradas em alguns contos religiosos da Pérsia e Índia, em plena Antiguidade. Ela acrescenta, em seu estudo, obras do Ocidente, que possivelmente tenham servido de inspiração para Shakespeare. Vejamos sua redação:

No Ocidente, as antigas leis romanas das Doze Tábuas deram a base legal para contos envolvendo esse tema. Conforme a Lei das Doze Tábuas, os credores, sob certas circunstâncias, poderiam dividir entre si o corpo do devedor. As histórias em torno desse assunto começaram a assumir uma forma moderna a partir do século XII, mas a primeira versão em língua inglesa do tema foi encontrada no poema Cursor Mundi (final do século XIII) e também tinha como credor um judeu.

Até aqui a figura do judeu é inserida em todas passagens, mas há o manuscrito Gesta Romanorum, coletânea de histórias medievais do século XIV, que foi traduzido por Richard Robinson dois séculos depois com duas versões em inglês, que não faz alusão

\footnotetext{
${ }^{4}$ Beatriz Viégas-Faria (2012) e Nelson Jahr Garcia.

${ }^{5}$ Dissertação de Mestrado. Vide referência bibliográficas. 
a ele, contudo mantém a história da libra de carne há menção, entretanto, à figura do judeu. (BONACIN, 2012)

Outras semelhantes podem ser encontradas em $A$ balada da crueldade de Germutus, O Orador, The Jew e O Judeu de Malta, entre outros que são objeto de estudos dessa autora.

\section{O contrato e a penalidade}

A partir do estabelecimento do contrato entre Bassânio, Antônio e Shylock, a história começa a tomar o rumo da pretensão que tem o judeu em se vingar da pessoa que mais the "judiou" ao longo de seus encontros.

Essa contratação institui os valores de três mil ducados a ser pago em três meses, conforme diálogo ${ }^{7}$ entre quem precisava do dinheiro e quem emprestaria:

$$
\begin{aligned}
& \text { Shylock - Três mil ducados, pois bem. } \\
& \text { Bassânio - Sim, senhor, por três meses. } \\
& \text { Shylock - Por três meses, pois bem. }
\end{aligned}
$$

Bassânio - Durante os quais, como eu Ihe expliquei, Antônio é o meu fiador.

Shylock - Antônio é o fiador, pois bem.

Bassânio - O senhor tem condições de me ajudar? Pode me fazer este obséquio? Poderia me dar uma resposta?

Shylock - Três mil ducados por três meses, e Antônio como fiador.

Em função de o necessitado não ter garantias pecuniárias para o empréstimo, Shylock se via diante de um momento ímpar: a possibilidade da desforra quando Bassânio disse que o seu amigo Antônio seria o fiador. Partiu para uma exigência que contrariava o direito à vida, mas que ensejava, se escrito, o cumprimento de um acordo que the permitiria executar o seu plano. Ele deixa claro para Antônio o porquê está fazendo essa exigência. Importante acompanhar uma parte do diálogo entre eles (Ato 1, cena III):

Shylock - Três mil ducados; é um bonito número, redondo. Três meses em doze, então deixem-me ver, à taxa de...

Antônio - Ora, Shylock, seremos então seus devedores?

Shylock - Signor Antônio, muitas e muitas vezes no Rialto o senhor me taxou disso e daquilo por causa dos meus dinheiros e

\footnotetext{
${ }^{6}$ Termo originado pela antiga tradição antissemita imputada aos judeus, que hoje se caracteriza como preconceito racial no seu uso, mas que neste artigo tem o caráter didático.

${ }^{7}$ Tradução de Beatriz Viégas-Faria (2012) 
das minhas taxas de juros. Sempre aceitei tudo com paciência, com um dar de ombros, pois este é o emblema[22] ${ }^{8}$ de toda a nossa tribo: resignar-se, sofrer em silêncio. O senhor me chama de infiel, de cão[23] ${ }^{9}$ raivoso, e cospe na minha gabardina de judeu. E tudo porque faço uso daquilo que é meu. Pois bem, agora parece que você está precisando de minha ajuda. $O$ que acontece? Você vem a mim e diz: "Shylock, nós queremos ter dinheiros"; é o que você diz, você que jogou o seu catarro nas minhas barbas e me chutou como quem enxota um vira-lata intruso porta afora, e você vem me pedir dinheiros. O que será que eu devo Ihe responder? Eu poderia perguntar: "Um cachorro tem dinheiro? Pode um cachorro emprestar três mil ducados?". Talvez eu devesse me curvar em profunda reverência e, no tom de voz de um escravo, com a respiração suspensa e com sussurrada humildade, eu devesse dizer: "Mui justo senhor, o senhor cuspiu em mim na última quarta-feira, o senhor me enxotou em um tal dia e, de outra feita, me chamou de cachorro; e, em consideração a essas cortesias, vou lhe emprestar estes tantos dinheiros."

Antônio - Estou a ponto de te chamar assim de novo, de cuspir em ti de novo, de te enxotar a pontapés também. Se queres emprestar esse dinheiro, empresta não como se fosse para amigos, pois quando é que um amigo toma de outro amigo a ninhada de seu estéril metal? Pelo contrário: empresta o teu dinheiro ao teu inimigo, àquele que, se for à bancarrota, tu podes com um sorriso no rosto cobrar dele a multa devida.

Shylock - Ora, veja só, como o senhor ficou irado! Meu desejo era ser seu amigo, e ter sua afeição, esquecer os insultos com que me manchou a mim, suprir suas necessidades de agora e não aceitar nem um tostão de juros pelos meus dinheiros, mas o senhor não quer me ouvir. Minha oferta é benevolente.

Bassânio - Deveras, isso seria benevolência.

Shylock - E meu desejo é provar essa benevolência. Venha comigo a um notário, me ponha o seu selo e a sua assinatura nessa letra promissória única e livre de condições... e, só por brincadeira, se você não me pagar o que deve no dia previsto, no local previsto, tal quantia ou quantias como descritas na promissória, que seja a multa exatamente uma libra de sua carne clara, a ser cortada e tirada de qualquer parte do seu corpo que eu nominar.

Antônio - Está bem, dou-lhe a minha palavra! Aponho o meu selo a essa promissória, e posso dizer que tem muita benevolência num judeu.

Nas últimas duas falas, as expressões "uma libra de carne" e "por brincadeira" sintetizam o cerne do produto de Shylock para a execução de seu plano. A primeira por se constituir, inicialmente ${ }^{10}$, pela literalidade em função de a história da violência humana estar internalizada pela questão racial cristianismo/judaísmo; a outra, pelo seu caráter

\footnotetext{
${ }^{8}$ Nota da tradutora Beatriz Viégas-Faria. Os judeus de Veneza eram obrigados a usar um distintivo na forma de um "O" amarelo.

${ }^{9}$ Idem. Para os judeus, os cães eram sinônimo de sujeira, imundície.

${ }^{10} \mathrm{Na}$ obra, o termo assumiu a literalidade inquestionável, mas neste artigo possibilita metaforizá-la.
} 
informal com o propósito de induzir a quem se submete a um acordo daquele nível a uma execução aparentemente imprópria.

\section{As expressões "uma libra de carne" e "por brincadeira"}

Primeiramente é importante ressaltar que os estudos linguísticos estão presentes em todas as áreas. E o alerta para os problemas de tradução se faz necessário para embasamento de nosso propósito. Especificamente neste artigo, um estudo de Lacan ${ }^{11}$, que gerou uma legião de pesquisadores de suas investidas no campo da linguagem, é apresentado por Inês Oseki-Dépré ${ }^{12}$ em seu artigo intitulado $A$ tradução brasileira dos Escritos de Jacques Lacan: de uma libra de carne. Para melhor ilustrar essa literalidade na obra O Mercador de Veneza, o excerto a seguir deixa o leitor, de certa forma, mais familiarizado com o tema, principalmente porque é necessária essa passagem literal para a metáfora da expressão:

Em suma, uma tradução que, nem por ser literal, se aproximaria disso o máximo possível. A segunda parte de sua exposição introduz, ainda a respeito de "re-elevante", um paralelo com Shylock, a personagem do Merchant of Venice. Derrida gostaria, diz ele, de "introduzir (sua palavra) no mercado" na espera de "um reconhecimento de divida". The Merchant dá ocasião a Derrida de justificar ao mesmo tempo a introdução da palavra "re-elevante6" na língua francesa e construir uma metáfora ${ }^{13}$ sobre a tradução pois trata-se nesse caso 1) de um engajamento, 2) de uma dívida; 3) do pagamento dessa dívida (que será anulada?); 4) da impossibilidade da tradução literal, da libra de carne ${ }^{14}$ (que corresponde a uma quantia de dinheiro mas cuja correspondência é impossível assim como é impossível a relação entre literalidade singular e a arbitrariedade do signo ${ }^{15}$ e 5) sua conversão em sentido. Lembrêmo-nos de que Shylock é enganado por Portia (disfarçada de advogada), que ele é impelido a "perdoar" sua dívida para salvar a vida de um homem e que esse perdão acarreta na anulação de sua dívida, na perda de seus bens e na sua conversão ao cristianismo,

Para isso, a fala de Shylock no original em inglês (ato 1, cena III) é indispensável para que se possa perceber a dualidade na tradução, mesmo com sutis diferenças, garantindo que a expressão determinante para o objetivo deste estudo foi utilizada no

\footnotetext{
11 Jacques-Marie Émile Lacan (1901-1981), psicanalista francês que buscou na linguística saussuriana a relação significante/significado e na antropologia estrutural deLévi-Strauss a base de seus escritos.

${ }^{12}$ Universidade de Provence. Tradutora de: Jacques Lacan, Escritos, São Paulo, Editora Perspectiva, 1978.

${ }^{13}$ Nosso grifo.

${ }^{14}$ Idem.

15 Idem; segundo Saussure, em seu Curso de Linguística Geral (1916), estabelece a relação significante/significado para o signo linguístico, em que o primeiro é a 'imagem acústica do som' e o segundo o 'conceito ou ideia' que o significante provoca.
} 
original. Trata-se aqui do diálogo em que Shylock aceita emprestar dinheiro, mas aplica a penalidade caso não seja feito o pagamento:

This kindness will I show. Go with me to a notary, seal me there. Your single bond; and, in a merry sport, if you repay me not on such a day, in such a place, such sum or sums as are express'd in the condition, let the forfeit be nominated for an equal pound of your fair flesh, to be cut off and taken In what part of your body pleaseth me.

Como foi mencionado anteriormente, as duas obras traduzidas contêm algumas diferenças de significado em função do entendimento contextual que cada um entende como mais apropriado, mas que mantêm inequivocadamente o conteúdo significativo do original, sobretudo a expressão "por brincadeira".

Na tradução de Nélson Jahr Garcia,

Quero dar-vos prova dessa amizade. Acompanhai-me ao notário ${ }^{16}$ e assinai-me o documento da dívida, no qual, por brincadeira ${ }^{17}$, declarado será que se no dia tal ou tal, em lugar também sabido. a quantia ou quantias não pagardes, concordais em ceder, por eqüidade, uma libra de vossa bela carne ${ }^{18}$, que do corpo vos há de ser cortada onde bem me aprouver.

e na de Beatriz Viégas-Faria,

E meu desejo é provar essa benevolência. Venha comigo a um notário, me ponha o seu selo e a sua assinatura nessa letra promissória única e livre de condições... e, só por brincadeira ${ }^{19}$, se você não me pagar o que deve no dia previsto, no local previsto, tal quantia ou quantias como descritas na promissória, que seja a multa exatamente uma libra de sua carne ${ }^{20}$ clara, a ser cortada e tirada de qualquer parte do seu corpo que eu nominar.

as expressões "por brincadeira" e "uma libra de carne" foram por ambos entendidas como as que correspondem às do original em inglês "in a merry sport" e "na pound of flesh", respectivamente.

\subsection{Literalidade}

\footnotetext{
${ }^{16}$ Indivíduo responsável pela elaboração de documentos públicos; tabelião (Houais, 2009)

${ }^{17}$ Grifo nosso.

${ }^{18}$ Idem.

${ }^{19}$ Idem.

${ }^{20}$ Idem.
} 
A literalidade da expressão "uma libra de carne" é inquestionável na obra. Não fosse assim, não seria possível aquele complexo julgamento, como também a literalidade de "por brincadeira", que é entendida nos dois textos, segundo Houaiss (2009), por

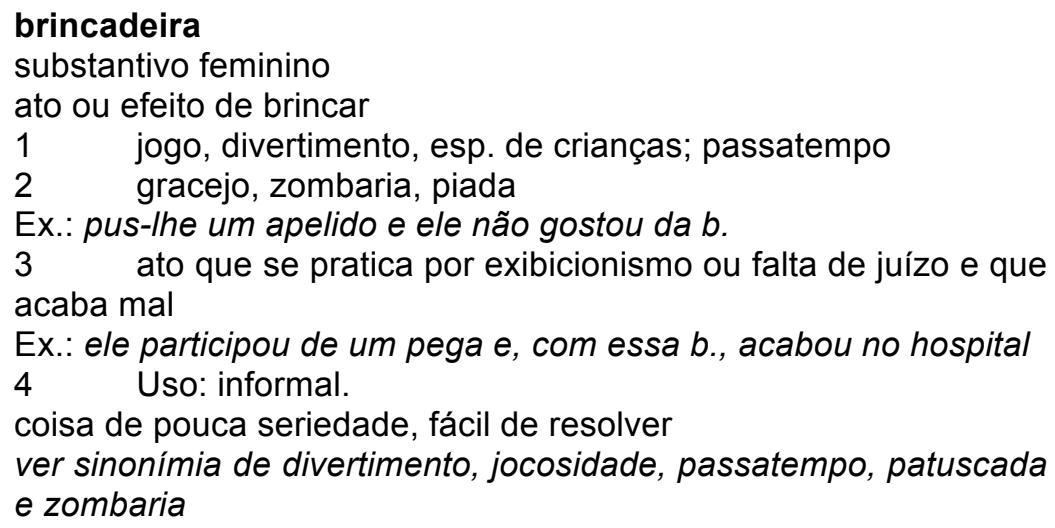

\subsection{Metáfora}

As metáforas são constituídas por expressões que têm seus significados diferentes dos que comumente são conhecidos nos dicionários. Seus significados são desviados do senso comum em contraposição à literalidade. Segundo Lakoff e Núnez (2000, p. 39),

Metáforas, durante muito tempo, vistas como figuras de linguagem, têm mostrado ser um processo central no pensamento do dia a dia. Metáfora não é apenas um ornamento; é o meio fundamental pelo qual o pensamento abstrato se torna possível. Um dos principais resultados nas ciências cognitivas é que os conceitos abstratos são tipicamente compreendidos, via metáfora, em termos de conceitos mais concretos.

Ferreira (2008) fez um estudo acerca das metáforas convencionais em que selecionou algumas expressões, dentre elas, To get a pound of flesh from human beings, em que traduz literalmente para tirar uma libra de carne dos seres humanos e no sentido metafórico é explorar alguém.

Essas relações de significado envolvendo a literalidade e a metaforização embasam a proposta deste estudo no que tange à alternativa que Shylock tinha para contra-argumentar no julgamento em que Antônio era o réu, diminuindo assim a penalidade revertida para ele própria em função da astúcia de Pórcia.

\section{O julgamento: Shylock tinha alternativa}


Como não foi possível o pagamento de Antônio para Shylock no prazo determinado, e também porque não interessava ao judeu qualquer valor pecuniário, e sim a multa proposta na ocasião em que deu o empréstimo a Bassânio e recebeu a nota promissória assinada com a fiança de Antônio, muito amigo de Bassânio. Com o contrato para ser executado, queria ele que a justiça fizesse jus ao que estava acordado entre eles: a multa para poder se vingar do cristão tirando "uma libra de carne" de qualquer parte do corpo do fiador.

Começa o julgamento com o Doge abrindo a sessão e já sugerindo ao reclamante para ter misericórdia do seu devedor. Ora, quando Shylock estabeleceu a multa daquele tipo, já estava com o firme propósito de derramar todo o ódio sentido pela forma com que era tratado pelo cristão Antônio, que agora estava sentado no banco dos réus.

Nenhum argumento convencia o credor para voltar atrás e receber a multa em dinheiro. Pelo contrário, Shylock exigia mais ainda que se fizesse justiça, inclusive provocando o Doge dizendo que as leis de Veneza eram uma vergonha.

Doge quase dissolveu o tribunal caso o Bellário, um erudito doutor em leis e a quem o duque mandou buscar para deliberar a questão, não chegasse a tempo para o pleito. Mas eis que chega um mensageiro com uma carta comunicando que Bellário seria substituído por Baltasar, um jovem advogado que conhecia muito bem a causa que defenderia. Na verdade, era a própria Nerissa, a dama de companhia de Pórcia, que levou a carta. As duas já tinham combinado para executarem o plano de se travestirem de homem para poder ajudar o amigo de seu esposo Bassânio. E Pórcia fazendo o papel do jovem advogado.

Enquanto isso, Graciano, amigo dos dois devedores, mantinha o discurso persuasivo para que Shylock desistisse de seu intento. Infrutíferas quaisquer investidas de quem quer que fosse. O judeu estava com ideia fixa e, de certa forma, desconfiado com o cumprimento da lei por parte de quem estava no comando do tribunal. E dizia frases fortes questionando a atuação da justiça.

Chega Pórcia e já toma o seu lugar para fazer a defesa do mercador, mas antes começa com um discurso para despertar a confiança de Shylock. Num dos diálogos iniciais, são estabelecidas as preliminares formais de identificação, ficando o judeu respondendo a todas com uma certa desconfiança.

Pórcia tenta em vão dissuadi-lo de seu propósito, mas sempre com indicativos de que estava tentando manter o seu direito de cobrar o que era devido, mesmo que não fosse moral. Ela pergunta aos devedores se querem fazer alguma proposta, no que de 
pronto Bassânio oferece três vezes mais o que devia, mas Shylock está irredutível. Pórcia, então, parte para a sua tática de convencimento e diz

- Esta promissória já venceu, e, por lei, segundo este documento, o judeu pode requerer a sua libra de carne, a ser cortada por ele o mais perto possível do coração do mercador. Seja piedoso: leve o triplo do dinheiro; peça-me para rasgar a promissória.

Com isso, Pórcia começa a aplicar um tipo de rabulice ${ }^{21}$ e o judeu começa a se entusiasmar e responde

- Quando ela estiver paga de acordo com o seu teor. Está me parecendo que você é um juiz de muito valor, que conhece a lei, e a sua preleção foi bastante sólida. Solicito que o senhor, de acordo com a lei, da qual o senhor é meritoriamente um pilar, proceda de imediato ao julgamento. Por minha alma, juro que não há força nas palavras de nenhum homem que possa modificar minha decisão. Esta é a minha posição: quero cobrar minha promissória.

Concomitantemente a isso, Antônio clama pelo veredito, resignando-se pela perda de sua vida, mas Pórcia não the dava ouvidos e continuava com o seu estratagema convencendo Shylock de que se faria justiça naquele tribunal. Mais alguns breves diálogos para se confirmar a preparação para a rabulice tomar corpo:

Pórcia - Mas, então, é isto: o senhor deve preparar o peito para a faca dele.

Shylock - Ah, que nobre juiz! Ah, que excelente jovem!

Pórcia - Não há dúvidas: a significação e a intenção da lei autorizam a cobrança da penalidade que, como nos mostra esta promissória, lhe é devida.

Shylock - É a mais pura verdade. Ah, que juiz sábio e correto! Sois tão mais velho que a vossa aparência!

Pórcia - Assim sendo, o senhor pode despir o seu peito.

Shylock - Sim, o seu peito. É o que diz a promissória, não é, nobre juiz? "O mais perto possível do coração": são essas exatamente as palavras.

Pórcia - É isso mesmo. Temos uma balança aqui, para pesar a carne?

Shylock - Tenho uma de prontidão.

Pórcia - Tenha também um médico de prontidão, Shylock, às suas custas, para estancar as feridas, para que ele não sangre até a morte.

Shylock - Isso está discriminado na promissória?

Pórcia - Isso não está discriminado, mas, e daí? Seria bom que o senhor agisse assim, por caridade.

Shylock - Não estou encontrando; não está escrito na promissória

Pórcia continua com a sua estratégia de fazer perguntas a todos, inclusive a Antônio, que diz estar preparado e pega a mão de Bassânio e lhe diz Adeus pedindo que

\footnotetext{
${ }^{21}$ Segundo Houaiss (2009), três significados: 1. ato, arrazoado ou procedimento próprio de rábula; rabularia; 2. palavras que nada provam ou concluem; rabularia; 3 . prática desleal cometida por advogado no decorrer do processo; chicana (Rubrica: termo jurídico).
} 
não sofra por ele porque não está arrependido de nada e acrescenta que fez tudo por amor. Por outro lado, Bassânio diz que preferia perdeu tudo para pô-lo em liberdade. Pórcia diz a ele que sua esposa gostaria de ouvir isso. O próximo foi o judeu a dizer algo, tendo respostas que Ihe agradavam muito:

Shylock - E são esses os maridos cristãos! Eu tenho uma filha; preferia que qualquer um da linhagem de Barrabás fosse seu marido, em vez de um cristão! Estamos perdendo tempo; peço-te que prossigas com a sentença.

Pórcia - Uma libra da carne deste mercador aqui é tua; esta corte te garante isso, e a lei te concede isso.

Shylock - Corretíssimo juiz.

Pórcia - E o senhor deve cortar a carne do peito dele. A lei permite, e este tribunal determina.

Shylock - Mui douto juiz! Que sentença! Vamos, prepare-se.

Nesta hora, Pórcia impõe a derrocada de Shylock, pois a sua rabulice se efetiva quando exige algo impossível de acontecer se a "libra de carne" for retirada:

Pórcia - Espere um minutinho, tem mais uma coisa. A promissória não prevê que te apropries do sangue do mercador. As palavras dizem expressamente "uma libra de carne". Então, pega a tua promissória e pega a tua libra de carne, mas, ao fazer o corte, se tu derramares uma única gota de sangue cristão, tuas terras e todos os teus bens serão confiscados pelas leis de Veneza e passarão a ser propriedade do Estado.

Graciano - Ah, que juiz honrado! Preste atenção, judeu... que juiz erudito!

Shylock - É essa a lei?

Pórcia - Tu mesmo podes ver o texto da lei. Pois, como tu clamavas por justiça, podes estar seguro de que terás mais justiça do que querias.

A partir de agora, Shylock se utilizaria de um recurso linguístico ${ }^{22}$, especificamente da área da Semântica:

Shylock - Já que é assim, então vamos retomar o contexto em que foi elaborado o contrato.

Pórcia - Prossiga em sua contra-argumentação.

Shylock - A multa "uma libra de carne" corresponde a uma expressão metafórica e eu quero que seja considerada como tal.

Pórcia - Sabe-se que a letra fria da lei é o que está escrito.

Shylock - As pessoas também se comunicam por metáforas, mesmo com o que está escrito.

Pórcia - Mas não é o caso.

Shylock - As metáforas são construídas na convivência das pessoas, constituindo-se como uma arbitrariedade do signo. Isso é convencional e o que se convenciona deve ser aceito.

Pórcia - A lei é outra coisa. Tem regras e vocabulário próprio.

Shylock - A língua também tem regras. Não fosse isso, não nos entenderíamos. E mais: o vocabulário é o mesmo, diferenciandose somente no que é formal e informal.

\footnotetext{
${ }^{22}$ As "novas falas" de Shylock doravante estarão em negrito e entre parênteses as "originais".
} 
Pórcia - Onde você quer chegar?.

Shylock - Que se entenda que a expressão é metafórica.

Portanto, não vou tirar nenhum pedaço físico de carne.

Shylock começa a virar o jogo porque Pórcia precisa provar que metáfora não pode ser aceita e não consegue.

Pórcia - Prove que a expressão é metafórica e não literal.

Shylock - Simples, tenho prova testemunhal de que utilizei explicitamente a expressão "por brincadeira".

Pórcia - "Por brincadeira" não estava escrito, o que vale é o que está na Nota Promissória.

Antônio, que estava assumindo a retirada de "sua carne", ouvindo o seu desafeto abrir mão da violência em uma manobra semântica e vendo a possibilidade de que a rabulice de Pórcia ficou enfraquecida, deu o seu aparte.

Antônio - Sugiro que se entre em um acordo.

Pórcia - Shylock, você está abrindo mão de violentar o seu devedor?

Shylock - Sim! A propósito, Vossa Excelência se utilizou de uma metáfora para me fazer pergunta.

Pórcia - Na língua falada é possível utilizá-la. Mas vamos ao que realmente interessa. Você não terá o pagamento de sua multa em "uma libra de carne" e nem o valor da proposta de receber três vezes o valor do empréstimo.

Shylock - Primeiramente, a metáfora interessa sim e foi com ela que consegui reverter a penalidade imposta por esse tribunal. Segundo, concordo em não me saciar do meu ódio histórico, mas não de não receber o que eu emprestei. Minha contraproposta então é receber o valor emprestado sem os juros.

Antônio, mais uma vez pede um aparte antes de a Pórcia se pronunciar e oferece o valor estipulado por Shylock.

Pórcia - Diante de tal celeuma e atendendo as partes interessadas, sentencio Shylock a não aplicar a sua multa mutilatória e a Antônio o pagamento do valor recebido por empréstimo sem que haja qualquer ônus de inadimplência. E está encerrada a sessão.

\section{Considerações finais}

Materializado um insight sobre como seria se "uma libra de carne" se constituísse em uma metáfora, como ficariam os diálogos na argumentação de Pórcia e na contraargumentação de Shylock, entendemos que o exercício ficcional jurídico-semântico conseguiu atingir a proposição inicial.

Constatamos, ao longo deste ensaio, que envolveu duas áreas completamente afins, que é indispensável gerar contextos potencialmente possíveis em cada área como 
também hibridizá-las em função da necessidade do exercício do senso literal e metafórico constantes. Assim, poderão ser vislumbradas circunstâncias que poderão ser desambigualizadas, se for o caso, com mais propriedade.

Especificamente quanto às expressões que constituíram o âmago deste artigo, "uma libra de carne" e "por brincadeira", podemos inferir, sem incorrer em erro, que existe a possibilidade de o Antônio ter sido ingênuo em não acreditar que ele estivesse falando na literalidade e também de ter a consciência de que o faria, mas de que a justiça não o atenderia, constituindo assim mais um objeto de estudo pela abordagem linguísticojurídica (ou jurídico-linguística?).

Quanto à eliminação dos diálogos finais da obra, torna-se necessário esclarecer que a possibilidade de mantê-los foi pensada, mas, diante da quantidade de que a presente peça contém e da restrição de páginas que se impõe a um artigo, convém ao leitor fazer um cotejamento dos diálogos a partir do momento em que Shylock não aceita a chicana aplicada pela Pórcia.

Fica aqui o nosso convite para suas incursões pelo universo dicotômico Direito e Linguagem.

\section{REFERÊNCIAS BIBLIOGRÁFICAS}

BONACIN, Larissa Degasperini. Shylock e O Mercador de Veneza: reflexões sobre questões de identidade e alteridade, ontem e hoje. Dissertação apresentada como requisito para a obtenção do Grau de Mestre ao Curso de Mestrado em Teoria Literária do Centro Universitário Campos de Andrade - UNIANDRADE. Curitiba, 2012.

DOMINIO PÚBLICO. http://www.dominiopublico.gov.br/download/texto/cv000094.pdf (acesso em 04/01/2014) -

FERREIRA, Luciana Correa. Metáfora conceitual e linguística de corpus. Pág. 156-167 (Apud Calidoscópio, São Leopoldo : Unisinos, 2008.

LAKOFF George, NÚÑES, Rafael. Where mathematics come from?New York: Basic Books, 2000. Apud Costa, Jorge Campos

SHAKESPEARE, William; tradução Beatriz Viégas-Faria. O mercador de Veneza. Porto Alegre, RS: L\&PM. Edição POCKET. 2012 
SHAKESPEARE, William. O Mercador de Veneza. Tradução de Nélson Jahr Garcia. Coleção Rindendo Castigat Mores. http://www.ebooksbrasil.org/eLibris/mercador.html (Acesso em 04/12/2013)

SHAKESPEARE, WILLIAM. O Mercador de Veneza. Versão em inglês. williamhttp://www.goodreads.com/ebooks/download/24128.The_Merchant_of_Venice (11/01/2014) "ou" http://shakespeare.mit.edu/merchant/index.html

UNIVERSIDADE DE PROVENCE . A tradução brasileira dos Escritos de Jacques Lacan: de uma libra de carne. Tradutora de: Jacques Lacan, Escritos, São Paulo, Editora Perspectiva, 1978. http://www.revue-silene.com/f/index.php?sp=comm\&comm_id=72, Acesso em 05/01/2014.

(Artigo submetido em 12/01/2013 e aceito para publicação em 28/12/2013) 